\title{
Does the Inadequate Health Resources Aggravate Covid-19 Pandemic?
} Jayadevan $\mathrm{CM}^{*}$

Swinburne University of Technology Department of Statistics, Data Science \& Epidemiology VIC 3122, Australia

DOI: $\underline{10.36347 / \text { sjams.2020.v08i07.002 }}$

| Received: 22.06.2020 | Accepted: 30.06.2020 | Published: 04.07.2020

*Corresponding author: Jayadevan CM

Abstract

Inadequate health resources to tackle affected patients can aggravate Covid-19 pandemic. There were 8.92 million Covid-19 cases, 0.47 million Covid-19 deaths and 4.74 million recovered Covid-19 cases in the world as on June 21 , 2020. Using a sample data of 117 countries until June 17, 2020, this study verifies and finds the support for the hypothesis that those inadequate health resources worsens Covid-19 pandemic.

Keywords: Covid-19, Health, Resources, Structural, Equation, Modeling.

Copyright @ 2020: This is an open-access article distributed under the terms of the Creative Commons Attribution license which permits unrestricted use, distribution, and reproduction in any medium for non-commercial use (NonCommercial, or CC-BY-NC) provided the original author and source are credited.

\section{INTRODUCTION}

The coronavirus COVID-19 is affecting 213 countries and territories around the world and 2 international conveyances [1]. The current coronavirus pandemic has seriously impacted the availability of goods and services, employment and living conditions of people all over the world. Covid-19 pandemic is the second largest human destructive pandemic after the Second World War in the last century. Apart from Covid-19, the human civilization has witnessed at least five pandemics in the current century. The outbreak of SARS caused by Coronavirus, Bats and Civets in 20022003 killed 700 people. The outbreak of Swine Flu during 2009-2010 killed 200,000 people. Mers pandemic caused by Coronavirus, bats or camels during 2015 to present killed 850 people. Ebola outbreak caused by Ebolavirus/Wild animals during 2014-2016 killed 11000 people [2]. Polio outbreak in 2014 was another pandemic of this century. Subsequently Covid19 outbreak has been declared as the sixth public health emergency of international concern on 30 Jan 2020 by the WHO [3].

We develop the remaining discussions as follows: Section II describes the descriptive statistics. The basic model is summarized in section III. Section IV reports the results of the study. Section V summarizes the findings and conclusions.

\section{Data Description}

The data used in this study to measure health resources has been obtained from World Bank indicators statistics [4]. The number of Covid-19 cases and deaths data are taken from worldometers [5]. A brief description of variables are provided in Table 1.

Table-1: Variables of Covid-19 and Human Resources

\begin{tabular}{|c|l|}
\hline Variables & \multicolumn{1}{|c|}{ Description of Variables } \\
\hline Covid-19 & Covid-19 latent factor \\
\hline CASES & Total number of Covid-19 cases \\
\hline DEATHS & Total number of Covd-19 deaths \\
\hline HEALTH & Health resources latent Factor \\
\hline PHY & Physicians (per 1,000 people) \\
\hline NMW & Nurses and midwives (per 1,000 people) \\
\hline DGGHE & Domestic general government health expenditure (\% of GDP) \\
\hline \multicolumn{2}{|c|}{$\begin{array}{r}\text { Source: Statistical Indicators Provided by World Bank } \\
\text { https://ourworldindata.org/coronavirus-source-data }\end{array}$} \\
\hline
\end{tabular}

There were 8.92 million Covid-19 cases, 0.47 million Covid-19 deaths and 4.74 million recovered Covid-19 cases in the world as on June 21, 2020. The average number of Covid-19 cases is 64849 and 3562 deaths. The highest number of Covid-19 cases is 2.14 million and the highest number of deaths is 0.12 million 
as on June 21, 2020. The coefficient of variation was highest for Covid-19 deaths followed by Covid-19 cases
(Table 2).

Table-2: Descriptive Statistics

\begin{tabular}{|c|c|c|c|c|c|c|}
\hline Variable & N & Mean & Std Dev & Minimum & Maximum & Coeff. Variation \\
\hline Cases & 124 & 64849.270 & 218881.790 & 104.000 & 2137731 & 337.523 \\
\hline Deaths & 124 & 3561.730 & 12684.130 & 11.000 & 116963 & 356.123 \\
\hline DGGHE & 124 & 3.700 & 2.380 & 0.420 & 10.990 & 64.324 \\
\hline PHY & 119 & 2.070 & 1.600 & 0.040 & 7.830 & 77.295 \\
\hline NMW & 120 & 4.660 & 4.220 & 0.100 & 17.990 & 90.558 \\
\hline \multicolumn{7}{|c|}{ Source: Computed from Statistical Indicators Provided by World Bank and } \\
https://ourworldindata.org/coronavirus-source-data \\
\hline
\end{tabular}

The average number of physicians per 1000 population is 2.07 . The highest number of physicians per 1000 population is 7.83 which is almost four times higher than the average number of physicians. The range for number of physicians per 1000 population is between 7.83 and 0.04 . There is a gap of 7.79 between minimum and maximum number of physicians per 1000 population (Table 2 ).

The average number of nurses and midwives per 1000 population is 4.66. The highest number of nurses and midwives is 17.99 which is almost four times higher than the average number of nurses and midwives. The range for number of nurses and midwives is between 17.99 and 0.10 . There is a gap of 17.89 between minimum and maximum number of nurses and midwives (Table 2).

\section{Model}

The Structural equation models for our data include variables that are proportions, numbers and ratios. Modeling of such "compound" quantities is less straightforward than absolute quantities. The use of factor analysis assumes that each of the observed variables being analyzed is measured on an interval or ratio scale [6]. So all the variables are rescaled using the min-max normalization formula $\mathrm{Y}_{\mathrm{i}}=\left(\mathrm{x}_{\mathrm{i}^{-}} \operatorname{minimum}(\mathrm{xi})\right.$ /maximum(xi) - minimum $\left(\mathrm{x}_{\mathrm{i}}\right)$. This type of manipulation of data results in the interval $[0,1]$ for all the variables. Labels of rescaled variables are identified by adding a prefix "V_" to the original variables.
Does the inadequate health resources aggravate Covid-19 pandemic? This research question is examined applying structural equation modeling (SEM) using the Covid-19 data as of June 21, 2020. Total number of Covid-19 cases and deaths are collected from Ourworldindata.org. Data on the number of physicians (PHY), nurses and midwives (NMW) and domestic general government health expenditure (DGGHE) are taken from World bank database. The number of physicians, nurses and midwives and government health expenditure represents average for five years from 2014 to 2018 .

The main reason for using the SEM method is necessitated by the use of latent variables in addition to manifest individual variables. A measurement model describes the nature of the relationship between a number of latent variables, or factors and the manifest indicator variables that measure those latent variables. The model investigated in this study consisted of two latent factors corresponding to the health resources and Covid-19. Latent variable health resources (F_HEALTH) are measured by two indicator variablesV_PHY (rescaled number of physicians) and V_NMW (recaled number of nurses and midwives). Latent variable Covid-19 pandemic (F_Covid) is measured by two indicator variables- V_CASES (rescaled number of Covid-19 cases) and V_DEATHS (rescaled number of Covid-19 deaths). Following two latent factors were created using factor analysis.

\section{F_COVID-19 $=\left(\mathrm{V} \_\right.$CASES + V_DEATHS $)$ F_HEALTH $=\left(\mathrm{V} \_\right.$PHY + V_NMW $)$}

Following structural equation is estimated and analysed.

$$
\text { F_COVID-19 = b1 F_HEALTH + V_DGGHE + e1 }
$$

Where F_HEALTH is health resources factor; F_COVID-19 is Covid-19 pandemic factor; V_PHY is the rescaled number of physicians; V_NMW is the rescaled number of nurses and midwives; V_DGGHE is the rescaled domestic government health expenditure; V_CASES is the rescaled total number of COVID-19 cases and V_DEATHS the rescaled total number of deaths caused by Covid-19 pandemic.; b1, is parameter; and $\mathrm{e} 1$ is the disturbance terms or residual path coefficient. Equation (1) represents the measurement model testing the hypothesis that inadequate health resources aggravate Covid-19 pandemic.

Data were analysed using the SAS 9.4 CALIS procedure, and the models tested were covariance structure models with multiple indicators for all latent constructs. The present analysis followed a two-step procedure based on the approach described by 
Anderson and Gerbing [7]. In the first step, confirmatory factor analysis was used to develop a measurement model that demonstrated an acceptable fit to data. In the second step, the initial measurement model was modified to become a structural equation model representing the theoretical model of interest. This theoretical model was then tested and revised until a theoretically meaningful and statistically acceptable model was achieved. Parameters are estimated applying two-stage least squares.

\section{RESULTS}

Final structural equation model is identified or met the t-rule criterion which states that sample moments or data points exceeds the number of free or distinct parameters. The number of data points is equal to the product of number of manifest variables and number of manifest variables plus one divided by two i.e., $((p([p+1]) / 2)$. The present analysis involves 5 manifest variables, 15 moments, 14 parameters and 117 cases. The parameter to case ratio is $1: 8$. This means we have 1 parameter to 8 cases. Since this is getting over 5 we could argue that the sample size is acceptable, but this also depends on other assumptions being met such as multivariate normality. A plot of the Mahalanobis distances is approximately normal though there are few outliers at the right side of the plot.

Table 3 reports the reliability estimates for the composite latent constructs. Composite reliability is a measure of internal consistency comparable to coefficient alpha. Cronbach's alpha is above 0.70 for both Covid-19 and health resource factors. This means responses to all five indicator variables demonstrate adequate reliability. The variance extracted estimate for each latent variable is a measure of the amount of variance captured by a construct, relative to the variance due to random measurement error. Both constructs demonstrated variance extracted estimates in excess of 0.50 , the level recommended by Fornell and Larcker [8]. These findings provide general support for the reliability and validity of constructs and their indicators. The standardized factor loadings for the indicator variables are also presented in Table.3. The standardized factor loadings are above $|0.6|$.

Table-3: Factor Loading and Reliability

\begin{tabular}{|l|l|l|l|}
\hline $\begin{array}{l}\text { Construct and } \\
\text { Indicators }\end{array}$ & $\begin{array}{l}\text { Standardized } \\
\text { Loading }\end{array}$ & $\begin{array}{l}\text { Reliability } \\
\text { (Cronbach's Alpha) }\end{array}$ & $\begin{array}{l}\text { Variance } \\
\text { Extracted estimate }\end{array}$ \\
\hline F_COVID-19 & & 0.962 & 0.964 \\
\hline V_CASES & 0.981 & & \\
\hline V_DEATH & 0.981 & & 0.860 \\
\hline F_HEALTH & 0.927 & 0.890 & \\
\hline V_PHY & & \\
\hline V_NMW & 0.927 & \\
\hline \multicolumn{3}{|c|}{ Source: Computed from Statistical Indicators Provided by World Bank and } \\
https://ourworldindata.org/coronavirus-source-data
\end{tabular}

In the present analysis, chi-square value is 1.043 with 1 degree of freedom, which is not significant (i.e., $\mathrm{p}>$ 0.307). Because it is not significant, technically we accept our null hypothesis of not good model fit. In other words, this test did support our model on the basis of chi-square (Table 4). The nomoligical validity of theoretical model is tested by performing a chi-square difference test in that baseline model is compared to the final measurement model. A chi-square difference test comparing final measurement model to base line model revealed a significant difference value of $456.311-1.043=455.268(\Delta \mathrm{df}=18$ $1=17, \mathrm{p}<0.01)$. This finding shows that final structural equation model provides a fit to data that is significantly better than the fit provided by the baseline model.

Table-4: Goodness of Fit Indices for Various Models

\begin{tabular}{|l|l|l|l|l|l|l|l|}
\hline Model & $\chi^{2}$ & df & $\Delta \chi^{2}$ & $\Delta$ df & CFI & SRMR & RMSEA(CL90) \\
\hline Baseline & 456.311 & 18 & & & & & \\
\hline Final Model & 1.043 & 1 & 455.268 & 17 & 0.999 & 0.020 & $0.019(0.000-0.248)$ \\
\hline \multicolumn{7}{|c|}{ Source: Computed from Statistical Indicators Provided by World Bank and } \\
https://ourworldindata.org/coronavirus-source-data \\
\hline
\end{tabular}

Other goodness-of-fit indices for the structural equation model is also presented in Table 4. The Comparative fit index (CFI), standardized Root Mean Square Residual (SRMR), and Root Mean Square Error of Approximation (RMSEA) as well as the $90 \%$ confidence limits for the RMSEA $\left(\mathrm{CL}_{90}\right)$ are examined to assess overall fit of data to the model.
The CFI is likely the most commonly reported incremental index, which Bentler [9] has described as the statistic of choice for analysis of covariance structures. According to $\mathrm{Hu}$ and Bentler [9], CFI values greater than 0.94 are suggestive of good fit between data and hypothesized models. In accord with the 
threshold values recommented by $\mathrm{Hu}$ and Bentler [9], the CFI value for the final model is ideal $(.99>.94)$.

The SRMR is an absolute index and is calculated as the standardized difference between observed and predicted correlation. A SRMR value of zero indicates perfect fit, whereas SRMR values less than 0.055 suggest good fit [9]. The SRMR value for the final model 0.02 is ideal $(0.02<0.055)$.

A commonly reported parsimony index is the RMSEA. As noted by Sun [10], the RMSEA is one of the most informative goodness-of-fit indices because it considers overall error in the population. RMSEA values less than 0.09 are suggestive of fair or adequate error of approximation. RMSEA value in this case is 0.019 which is acceptable. However, $90 \%$ confidence limits $(0.000-0.25)$ for the RMSEA are not within acceptable parameters range $(0.05-0.08)$.

It is still necessary to inspect specific features of the model results to see if any of the individual features fail to receive support even if most of the overall fit indices indicates good fit. Paths were deleted as per the results of Lagrange multiplier. In other words, this finding indicates that the relationships described in final model are successful in accounting for the observed relationships between the latent constructs.

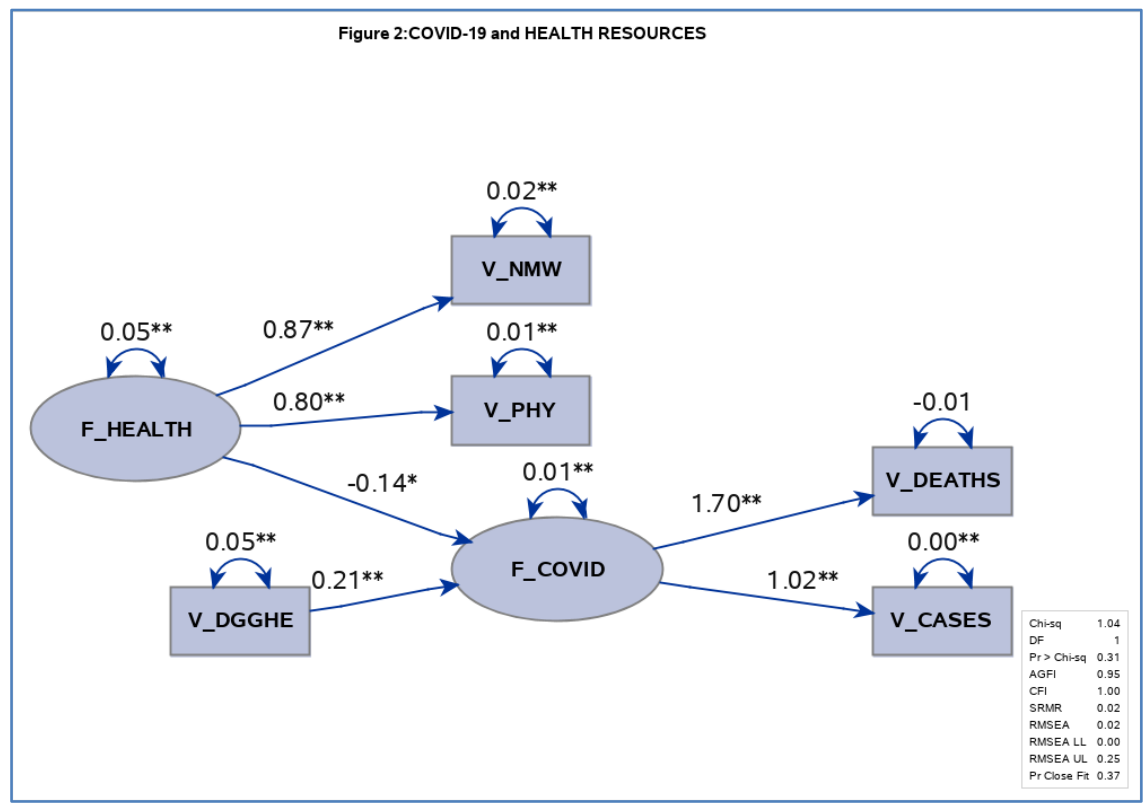

Fig-1

Figure 1 depicts non-standardized path coefficients of the final model. Path flow shows the coefficient of non-standardized coefficients reported in Table 5. Significance tests for path coefficients appeared under the heading "non-standardized results" and "standardized results".

One-unit increase in Covid-19 increases Covid-19 cases by 1.07 units in non-standardized model or by 0.77 units in standardized model. One-unit increase in Covid-19 increases Covid-19 deaths by 1.69 units in non-standardized model or by 1.21 units in standardized model (Table 5).

One unit increase in health resource increased number of physicians by 0.80 units in non-standardized model or by 0.87 units in standardized model. One-unit increase in health increases nurses and midwives by 0.87 units in non-standardized model or by 0.82 units in standardized model (Table 5).
The regression weight of health resources factor on Covid-19 is -0.14 in non-standardized model and -0.38 in standardized model. The regression coefficient of health resources factor on Covid-19 is negative and significant. This indicates that for a oneunit increase in health resources, there is a decrease of 0.14 units in Covid-19 in non-standardized model and there is a decrease of 0.38 units in standardized model while controlling the effects of the other independent variables which confirms the support for the hypothesis. The estimated structural equation model shows that the Covid-19 pandemic is aggravated by inadequate health resources. Inadequate health resources negatively and significantly contributes to the development of Covid19 (Table 5). Government health expenditure could not directly reduce Covid-19 as seen from the significant positive coefficient of government health expenditure. 
Table-5: Results for Path List

\begin{tabular}{|c|c|c|c|c|c|c|c|c|}
\hline \multicolumn{3}{|l|}{ Path } & \multicolumn{3}{|c|}{ Non-standardized Results } & \multicolumn{3}{|c|}{ Standardized Results } \\
\hline & & & Estimate & t Value & $\operatorname{Pr}>|t|$ & Estimate & t Value & $\operatorname{Pr}>|t|$ \\
\hline F_COVID & $===>$ & V_CASES & 1.017 & 6.822 & $<.0001$ & 0.768 & 9.686 & $<.0001$ \\
\hline F_COVID & $===>$ & V_DEATHS & 1.695 & 20.618 & $<.0001$ & 1.208 & 10.290 & $<.0001$ \\
\hline F_HEALTH & $===>$ & V_PHY & 0.804 & 19.721 & $<.0001$ & 0.874 & 26.351 & $<.0001$ \\
\hline F_HEALTH & $===>$ & V_NMW & 0.871 & 23.018 & $<.0001$ & 0.824 & 21.699 & $<.0001$ \\
\hline F_COVID & $<===$ & V_HEALTH & -0.136 & -2.269 & .023 & -0.383 & -2.177 & 0.029 \\
\hline F_COVID & $<===$ & V_DGGHE & 0.207 & 3.144 & .002 & 0.587 & 2.917 & 0.003 \\
\hline
\end{tabular}

\section{Conclusion}

The estimated structural equation model shows that the Covid-19 pandemic in a country depends on the level of health resources. Inadequate health resources negatively and significantly contribute to the faster development of Covid-19 pandemic. Statistical power for this final model is very high. Most of the goodnessof-fit indices for final model are ideal parameters. Path coefficient between Covid-19 pandemic and health resource factor is negative and statistically significant. Health resources containing physicians, nurses and midwives have a significant role in reducing Covid-19 pandemic. It is a good idea to maintain a reserve of health resources to tackle this kind of destructive pandemic.

Though this study selected all the countries, in the actual analysis, the size of sample was contracted to 117 countries depending on the data availability because the records with the missing observations were excluded. There were no past studies analysing the relationship between Covid-19 pandemic and health resources factors using the structural equation modeling so this study is new in the context of methodology.

\section{REFERENCES}

1. https://www.worldometers.info/coronavirus/?utm_c ampaign=homeAdUOA?Si, June 21, 2020.

2. LePan, Nicholas. 2020. https://www.visualcapitalist.com/history-ofpandemics-deadliest/ March.

3. Chakraborty, Indranil, Maity, Prasenjit. COVID-19 outbreak: Migration, effects on society, global environment and prevention. 2020; 728.
4. World Bank. 2020. World Development Indicators (WDI). Washington, DC. http://datatopics.worldbank.org/worlddevelopment-indicators/

5. https://www.worldometers.info/coronavirus/.(June 25, 2020).

6. Rourke, Norm O'. Hatcher, Larry. A Step-by-Step Approach to Using SAS for Factor Analysis and Structural Equation Modeling. $2^{\text {nd }}$ Edition. 2013. SAS.

7. Anderson JC, Gerbing DW. Structural equation modeling in practice: A review and recommended two-step approach. Psychological bulletin. 1988 May;103(3):411.

8. Fornell C and Larcker DF. Evaluating Structural Equation Models with Unobservable variables and Measurement Error. Journal of Marketing Research.1981; 18, 39-50.

9. Hu, LT and Bentler PM. Cutoff criteria for fit indices in covariance structure analysis: Conventional criteria versus new alternatives. Structural Equation Modeling. 1999; 6, 1-55.

10. Sun J. Assessing goodness of fit in confirmatory factor analysis. Measurement and Evaluation in Counseling and Development. 2005; 37: 240-256.

11. Byrne BM. Structural Equation Modeling with AMOS: Basic Concepts, applications and Programming ( $2^{\text {nd }}$ Ed.). Mahwah, NJ: Lawrence Erlbaum; 2009.

12. Ritchie, Hannah. https://ourworldindata.org/coronavirus-sourcedata.2020; June 212020. 